\title{
Durability of Wood Exposed to Alternating Climate Test and Natural Weathering
}

\author{
Alexander Stadlmann ${ }^{1, *}$, Maximilian Pramreiter ${ }^{1}\left[\right.$, Robert Stingl ${ }^{1}$, Christian Kurzböck ${ }^{2}$, \\ Thomas Jost ${ }^{2}$ and Ulrich Müller ${ }^{1}$ \\ 1 Institute of Wood Technology and Renewable Materials, Department of Material Science and Process \\ Engineering, University of Natural Resources and Life Sciences Vienna, Austria (BOKU), Konrad Lorenz \\ Strasse 24, 3430 Tulln a.d. Donau, Austria; maximilian.pramreiter@boku.ac.at (M.P.); \\ robert.stingl@boku.ac.at (R.S.); ulrich.mueller@boku.ac.at (U.M.) \\ 2 Virtual Vehicle Research GmbH, Inffeldgasse 21/A, 8010 Graz, Austria; christian.kurzboeck@v2c2.at (C.K.); \\ thomas.jost@v2c2.at (T.J.) \\ * Correspondence: alexander.stadlmann@boku.ac.at; Tel.: +43-1-47654-89151
}

Received: 10 August 2020; Accepted: 30 August 2020; Published: 31 August 2020

check for updates

\begin{abstract}
The use of wood-based materials in the automotive industry is currently under discussion and investigation. One of the major material requirements for such applications is sufficient weathering stability. This can be demonstrated by an accelerated aging process in which the samples are exposed to changing climatic conditions and a spray mist of an aqueous $\mathrm{NaCl}$ solution. The effects of media salt $(\mathrm{NaCl})$ on the mechanical and physical properties of wood have scarcely been investigated. The presented study investigated the changes in bending strength (MOR), modulus of elasticity (MOE), and impact bending strength ( $\alpha$ ) of naturally and artificially weathered oak (Quercus spp.) and birch (Betula pendula Roth) wood. The tests provided comparable results. The decrease under natural weathering of oak was $3.73 \%, 4.69 \%$, and $6.45 \%$ for MOR, MOE, and $\alpha$. Under artificial weathering the decrease observed for oak was $7.33 \%, 10.87 \%$, and $16.29 \%$ and $3.2 \%, 8.21 \%$, and $4.03 \%$ for birch respectively. It is remarkable that $\alpha$ increased for birch wood at the beginning of the artificial weathering cycles. The penetration of the aqueous $\mathrm{NaCl}$ solution into the wood substance resulted in an increase in the wood's equilibrium moisture content (EMC), which can be explained by the stronger hygroscopic properties of $\mathrm{NaCl}$ compared to wood. The higher impact strength at the beginning of artificial weathering can be partly explained by this increase in EMC. In order to investigate the penetration behavior of salt into the wood substrate, the artificially weathered samples were examined by means of energy dispersive X-ray analysis (EDX) and it was shown that the salt concentration changes significantly over the weathering cycles and sample cross-section.
\end{abstract}

Keywords: aging effects; artificial weathering; bending strength; birch; durability; impact bending strength; $\mathrm{NaCl}$; oak; sodium chloride

\section{Introduction}

By reducing the tare weight in automotives, the highest potential savings in fuel consumption can be achieved. This leads to multi-material lightweight designs in automotive engineering. Components commonly used in such multi-material applications are based on steel, aluminium, plastics, and lightweight materials like carbon- or glass fibre composites [1,2]. However, the increasing use of material combinations requires high engineering capacities and rising production costs, which ultimately increase overall costs of vehicle production. Wood products are mass products that can be manufactured with noticeably short processing times at low costs. Due to the extremely high productivity of the wood industry, the same or shorter process times are assumed for simple 2D 
geometry elements in wood hybrid construction compared to components made of metal or plastic. Beside ecological reasons, the high availability at low raw material costs is another benefit for the use of wood. The carbon footprint of fibre reinforced plastics poses an additional disadvantage [3]. As an alternative to constructions with fibre- reinforced plastics, the use of wood composites, as a structural design element in automotive engineering, has been increasingly discussed in recent years [4-6]. On the one hand, wood is a sustainable, bio-based material and on the other hand the technical feasibility of wood in vehicle design has been demonstrated by several studies $[4,6,7]$. Therefore, the efficient and intelligent use of sustainable and renewable bio-based materials can contribute to the reduction of greenhouse gas emissions and thus tackle climate change [8,9]. Potential applications for intelligent wood-based hybrid structures are load-bearing or crash-absorbing components [10]. When using wood and wood composites correctly, they can compete with the currently used materials $[2,10]$. Especially the ratio between mechanical properties and density makes wood highly competitive with steels and manmade fibre composites.

New fields of wood and wood product applications such as the automotive industry, demand knowledge about the material behaviour, the predictability, shaping and joining techniques, and coat ability. Investigations on this have been carried out by various authors with regards to wood and wood-based composites [7,11-14].

Load-bearing structures in vehicles are permanently exposed to external environmental influences. The media resistance and corrosion of materials due to moisture and salt and the resulting changes in properties have therefore been well investigated in the past using the corresponding methods and standards [15-17]. However, such investigations are lacking for wood composites and wood hybrid constructions and changes of physical and mechanical properties of wood due to treatment with saline solutions have been scarcely investigated. Almost all European wood species have a moderate to low natural durability. In order to prevent decay, there are two approaches for increasing the durability, the chemical and constructive protection, which have been well studied [18]. Müller et al. [19] described, that without waterlogging or direct UV radiation, structural elements of 70 year old wooden aircraft showed no or only a slight decrease in mechanical properties. It is therefore assumed, that wood-based components, correctly used with surface treatment and constructive wood protection, can also be used without hesitation in the automotive industry. After research programmes have clarified the technical feasibility of computability and fundamental process engineering questions concerning joining, shaping, and coating of wood composites for vehicle applications [20-22], knowledge about media resistance is required. As mentioned above, there is little knowledge on artificial aging, or more precisely, the effect of salt and moisture or both in combination on solid wood and wood products. Beside the weatherability and durability of such components, excluding the biological decay in this study, it is necessary to investigate and describe changes in the mechanical and physical properties of wood and wood-based materials.

Living trees, especially mangroves or grassy plants in Wadden sea salt marshes have a good ability to tolerate saline environments with various effects on growth and morphological characteristics $[23,24]$. With regard to the ageing of wood under storage in a saline environment, the wood chemistry changes due to deacetylation and degradation of hemicelluloses [25]. It has therefore been concluded, that the wood substance is not corroded by saline solutions in the way steel is. Nevertheless, due to the chemical properties of $\mathrm{NaCl}$, it can be assumed that the exposure of wood to saline solutions leads to an altered hygroscopic behaviour of wood.

In this study artificial and natural weathering of oak wood (Quercus spp.) and artificial weathering of birch wood (Betula pendula Roth) was investigated. To compare the natural weathering, oak wood samples were stored under outdoor conditions for 14 years and compared with reference samples stored under standard climate conditions and with artificially aged samples. For the artificial weathering of oak and birch wood samples, alternating climate tests were carried out according to the automotive standard DIN EN ISO 11997-1 [26]. In order to quantify the change in mechanical properties due to possible weathering effects, the samples were tested in a 3-point bending test according to the standard 
DIN 52186 [27] and an impact bending test according to the standard DIN 52,189 [28], both of which are commonly used in wood science and technology. Furthermore, the changes of the equilibrium moisture content (EMC) after natural and artificial weathering of all samples were investigated. The salt concentration within the wood samples was investigated by means of EDX-analysis.

It is hypothesized, that wood has a good resistance to various weather conditions and the influence of salt has only a minor effect on the hygroscopic behaviour of wood. Therefore, only minor changes are expected for bending strength and impact bending strength due to artificial weathering. It is assumed that the requirements of the automotive industry for media resistance with regard to saline solution should therefore not be a limitation for structural application in the automotive industry.

\section{Materials and Methods}

To avoid knots and fibre deviation in the test specimens, visually sorted oak wood (Quercus spp.) and birch (Betula pendula Roth) wood samples were used for this study. Conventionally, dried oak and birch wood were sourced from the company Frey-Amon (Hetzmannsdorf, Austria). All specimens were cut out of the boards using a circular saw, weathered, and tested without sanding or any surface coating.

\subsection{Natural Weathering}

The natural weathering was carried out on oak wood samples. For these experiments $150 \mathrm{~mm}$ wide and $26 \mathrm{~mm}$ thick boards with a corrugated profile were used. The wooden boards were stored without any ground contact in two different orientations. On the one hand at an angle of $45^{\circ}$ to the ground and on the other hand parallel to the ground. In order to exclude any influence of the weathered surface on the mechanical properties, the boards were planed to a final thickness of $20 \mathrm{~mm}$, with the profiled surface planed $4 \mathrm{~mm}$ and the opposite surface planned $2 \mathrm{~mm}$, before testing. At the beginning of the weathering experiment in the year 2005, the samples were stored on the rooftop at the University of Natural Resources and Life Science (Peter Jordan-Straße 82, Vienna, Austria) where environmental influences such as rain, snow, sun, and wind affected the sample material unhindered. Due to the relocation of the institute to the University-Research-Center-Tulln (Kondrad Lorenz-Straße 24, Tulln/Donau, Austria), the samples were transferred to Tulln after seven years of exposure. It can be assumed that due to the similar climatic conditions of Vienna and Tulln no significant changes in natural weathering conditions were caused by this relocation. In total the samples were stored outside for 14 years and 78 days. For comparison, reference samples for natural weathering were stored indoors under standard climate conditions for the same period according to standard ISO 554 [29]. Measured values during the weathering period were the temperature, the precipitation, the relative humidity, and the introduced global radiation.

As seen in Table 1, the mean value of the daily temperature in the field weathering test was about $11^{\circ} \mathrm{C}$ whereby the lowest temperature observed was $-18.5^{\circ} \mathrm{C}$ and the highest temperature was $37.1^{\circ} \mathrm{C}$. The peak wind speed observed in this study was about $120 \mathrm{~km} / \mathrm{h}$ and the average was about $8 \mathrm{~km} / \mathrm{h}$. During the entire weathering period, almost 10,000 L/m² precipitation was observed, with peak values of $78.6 \mathrm{~L} / \mathrm{m}^{2}$ per day. The mean value of measured relative humidity is about $75 \%$, whereby maximum values ranged between $5 \%$ and $100 \%$. The conditions of natural weathering in Vienna and Tulln show a representative cross-section for the Central European region. It is therefore assumed that these conditions are also representative for the mobility sector and the results allow a rough estimation of the natural durability of wood. 
Table 1. Overview of the observed climate data of the weathering period: Wind speed, global radiation, temperature, relative humidity, and precipitation.

\begin{tabular}{|c|c|c|c|c|c|}
\hline & $\begin{array}{l}\text { Wind Speed } \\
(\mathbf{k m} / \mathrm{h})\end{array}$ & $\begin{array}{c}\text { Global Radiation } \\
\left(\mathrm{MJ} / \mathrm{m}^{2}\right)\end{array}$ & $\begin{array}{c}\text { Temperature } \\
\left({ }^{\circ} \mathrm{C}\right)\end{array}$ & $\begin{array}{l}\text { Relative Humidity } \\
\text { (\%) }\end{array}$ & $\begin{array}{l}\text { Precipitation } \\
\left(\mathrm{L} / \mathrm{m}^{2}\right)\end{array}$ \\
\hline Sum & - & 58,544 & - & - & 9935 \\
\hline Mean value & 8 & 11 & 11 & 75 & 2 \\
\hline max. & 120 & 32 & 37 & 100 & 79 \\
\hline $\min$. & 0 & 0 & -19 & 5 & 0 \\
\hline
\end{tabular}

\subsection{Artificial Weathering}

Oak and birch solid wood samples, with a dimension of $20 \times 20 \times 400 \mathrm{~mm}$ were exposed to an alternating cyclic corrosion test according to the standard DIN EN ISO 11997-1 cycle B [26] in a climate chamber (VLM, CCT 3000-FL-B, Bielefeld, Germany) with alternating climate. A salt solution with $5 \mathrm{wt} \%$ sodium chloride sprayed as a fog was used at a regulated $\mathrm{pH}$-value of 6.5 to 7.2 . The detailed cyclic climate-procedure is presented in Table 2 . In general, the specimens were artificially weathered for 20 weeks ( $3360 \mathrm{~h}$ ). In the case of oak solid wood, 7 reference samples (non-weathered) and 7 samples after 20 weeks artificial weathering were tested.

Table 2. Climate-parameters for the cyclic corrosion test; cycle B according DIN EN ISO 11997-1: Stage, duration time, temperature, condition, and comments.

\begin{tabular}{|c|c|c|c|c|}
\hline Stage & Time (h) & Temperature $\left({ }^{\circ} \mathrm{C}\right)$ & Condition & Comment \\
\hline 1 & 24 & $35 \pm 2$ & Salt spray & \\
\hline 2 & 8 & $40 \pm 2$ & $100 \%$ rel. humidity & Water condenses on the sample \\
\hline 3 & 16 & $23 \pm 2$ & $(50 \pm 20) \%$ rel. humidity & - \\
\hline 4 & 8 & $40 \pm 2$ & $100 \%$ rel. humidity & Water condenses on the sample \\
\hline 5 & 16 & $23 \pm 2$ & $(50 \pm 20) \%$ rel. humidity & - \\
\hline 6 & 8 & $40 \pm 2$ & $100 \%$ rel. humidity & Water condenses on the sample \\
\hline 7 & 16 & $23 \pm 2$ & $(50 \pm 20) \%$ rel. humidity & - \\
\hline 8 & 8 & $40 \pm 2$ & $100 \%$ rel. humidity & Water condenses on the sample \\
\hline 9 & 16 & $23 \pm 2$ & $(50 \pm 20) \%$ rel. humidity & - \\
\hline 10 & 48 & $23 \pm 2$ & $(50 \pm 20) \%$ rel. humidity & \\
\hline 11 & \multicolumn{3}{|c|}{ back to stage 1} & $\begin{array}{l}\text { Total duration of a cycle from } \\
\text { stage } 1 \text { to stage } 10 \text { of } 7 \text { days }\end{array}$ \\
\hline
\end{tabular}

In order to examine the influence of the weathering cycles on the properties of the samples, a complete set of a sample for birch solid wood was taken every 2 weeks for further characterisation (3-point bending test and impact bending test). Therefore, one cycle consists of 2 weeks of artificial weathering and 20 weeks is equal to 10 cycles. In total a set of 7 samples per cycle and per test setup were artificially weathered (total 140 specimens for birch wood).

\subsection{Mechanical Properties}

The density ( $\rho$ ) of the samples was calculated according to the standard DIN 52,182 [30] using their volume $(\mathrm{V})$ and mass $(\mathrm{m})$.

To evaluate the possible influence of the different weathering cycles on the equilibrium moisture content (EMC), all specimens were stored under standard climate conditions at $20 \pm 2{ }^{\circ} \mathrm{C}$ and $65 \pm 5 \%$ relative humidity $(\mathrm{RH})$ in accordance with standard ISO 554 [29] prior to mechanical testing. In addition, the change in hygroscopic behaviour was assessed by the additional introduction of a reference test set (specimens' dimension: $20 \times 20 \times 20 \mathrm{~mm}$ ), in which eight birch and oak wood samples were submerged in a salt solution with $5 \mathrm{wt} \% \mathrm{NaCl}$ for one week in a desiccator. After that, the specimens were stored at standard climate conditions till EMC was reached. Afterwards, the specimens were oven dried at 
$103^{\circ} \mathrm{C}$ and the EMC was calculated. This reference test set was carried out to assess and validate the change in hygroscopic behaviour after submersion in salt water.

The impact bending test was conducted according to the standard DIN 52,189 [28] with a pendulum machine (Wolpert, Vienna, Austria). For each species and climate cycle 7 specimens with a dimension of $20 \times 20 \times 300 \mathrm{~mm}(\mathrm{R} \times \mathrm{T} \times \mathrm{L})$ were produced and tested at standard climate. To calculate the impact bending strength Equation (1) was used:

$$
\alpha=\frac{W}{b \times h}
$$

where $W$ is the work required to break the specimen, $b$ the width, h the thickness, and $\alpha$ the impact bending strength.

The bending strength (MOR) and the bending modulus of elasticity (MOE) were determined according to the standard DIN 52,186 [27] in a 3-point bending test. The experiment was performed on a universal testing machine (Zwick/Roell Z100, Ulm, Germany). Therefore, specimens with a dimension of $20 \times 20 \times 360 \mathrm{~mm}(\mathrm{R} \times \mathrm{T} \times \mathrm{L})$ were used and for prior testing, the samples were climatized at standard climate.

\subsection{Microscopic Inspection}

In order to determine the elementary distribution within the sample and the penetration behaviour of $\mathrm{NaCl}$ into the wood structure, microscopic inspection by means of scanning electron microscopy (SEM) was conducted. After mechanical experiments two samples of cycle one, two, three, six, and ten for birch solid wood were analysed by means of SEM (FEI Quanta ${ }^{\text {TM }} 250$ FEG, Hillsboro, OR, USA). In this study, no elemental analysis was performed for additional cycles and reference samples. It was assumed that the data points could be interpolated in between the cycles. To determine the elementary distribution within the cross section of a sample an energy dispersive X-ray detector (Ametek materials Analytics Division, Berwyn, PA, USA) was used. For this purpose, two specimens of each selected cycle with a dimension of about $2 \times 20 \mathrm{~mm}$ were cut out close to the fracture surface using a doublebladed circular saw as shown in Figure 1.
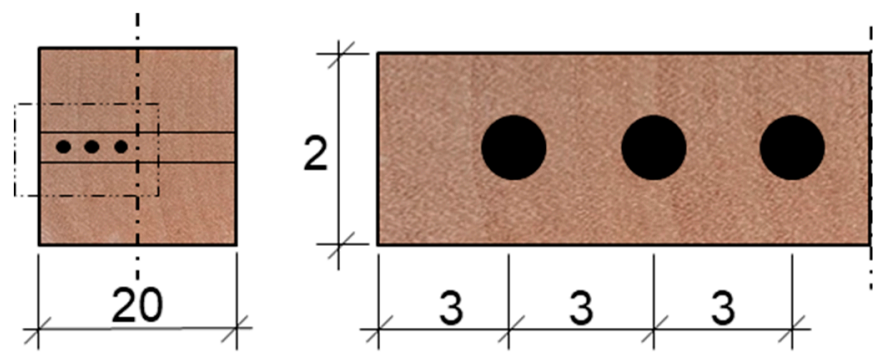

Figure 1. Sample geometry and measuring spots for energy dispersive X-ray analysis (EDX) used to determine the elementary distribution of sodium chloride within the sample cross section.

Afterwards, the cross section was prepared with a razor blade to obtain a smooth surface without any contamination. EDX analysis was carried out on 3 measuring spots from the edge to the middle of the specimen. The measurements were taken at a high vacuum of $2.3 \times 10^{-3} \mathrm{mbar}$. In order to evaluate the amount of the elementary distribution, the atomic percentage of carbon, oxygen, sodium, and chlorine were evaluated and plotted as mean value. 


\subsection{Statistics}

In this study a multi-factorial ANOVA model with an error level of 0.05 was calculated using Excel 2016 (Microsoft, Redmond, Washington, DC, USA) to evaluate the relationship between $\rho$, MOE, MOR, $\alpha$, and $\omega$ for artificial weathering at the processed cycles For natural weathering ANOVA was applied to investigate the relationship of the reference samples and the samples of cycle 10.

\section{Results and Discussion}

\subsection{Sample Properties}

The moisture content of wood has a significant influence on the mechanical and physical properties of wood. As reported by Kollmann [22] and Niemz [31], the bending MOE and MOR decreases with increasing moisture content below fibre saturation point. In terms of impact bending strength of air- dried wood, moisture has only a minor influence [22]. Depending on temperature and relative humidity, a specific wood moisture content, the so-called wood equilibrium moisture content (EMC), is established. As described by Kollmann [22], the Loughborough diagram shows the respective EMC for different combinations of temperature and relative humidity. Although performed for Sitka Spruce, the Loughborough diagram also provides the EMC for other wood species with sufficient accuracy for the different climatic conditions.

The introduction of salt during artificial weathering into the wood structure, changes the hygroscopic properties and thus the equilibrium moisture content of wood, and therefore influences the mechanical properties. The results of the reference test set of the altered EMC of birch and oak wood samples stored in salt solution are presented in Table 3. The birch samples submerged in $\mathrm{NaCl}$-solution showed a significant increase in EMC from $10.35 \%$ to $11.81 \%$. For oak the EMC increased significantly from $11.36 \%$ to $11.97 \%$. Based on these results, it can generally be assumed that artificially weathering leads to a higher EMC. Zones within the samples with high salt concentrations thus exhibit higher EMC than zones with little or no salt deposition. To investigate the sodium concentration over the cross section of the artificial weathered samples, the sodium chloride concentration was measured by means of EDX analysis (see Figure 2).

Table 3. Overview of the altered equilibrium moisture content (EMC) of the reference test set after storage in salt solution for birch and oak wood investigated at standard climate conditions at $20{ }^{\circ} \mathrm{C} \pm 2{ }^{\circ} \mathrm{C}$ and $65 \% \pm 5 \%$ relative humidity $(\mathrm{RH})$.

\begin{tabular}{ccccc}
\hline $\begin{array}{c}\text { Statistical } \\
\text { Indicator }\end{array}$ & $\begin{array}{c}\text { Birch Reference } \\
\text { EMC (\%) }\end{array}$ & $\begin{array}{c}\text { Birch Altered } \\
\text { EMC (\%) }\end{array}$ & $\begin{array}{c}\text { Oak Reference } \\
\text { EMC (\%) }\end{array}$ & $\begin{array}{c}\text { Oak Altered } \\
\text { EMC (\%) }\end{array}$ \\
\hline$n$ & 8 & 8 & 8 & 8 \\
mean & 10.35 & 11.81 & 11.36 & 11.97 \\
SD & 0.63 & 0.18 & 0.58 & 0.14 \\
min. & 9.70 & 11.44 & 10.32 & 11.82 \\
max. & 11.33 & 12.06 & 11.84 & 12.20 \\
\hline
\end{tabular}




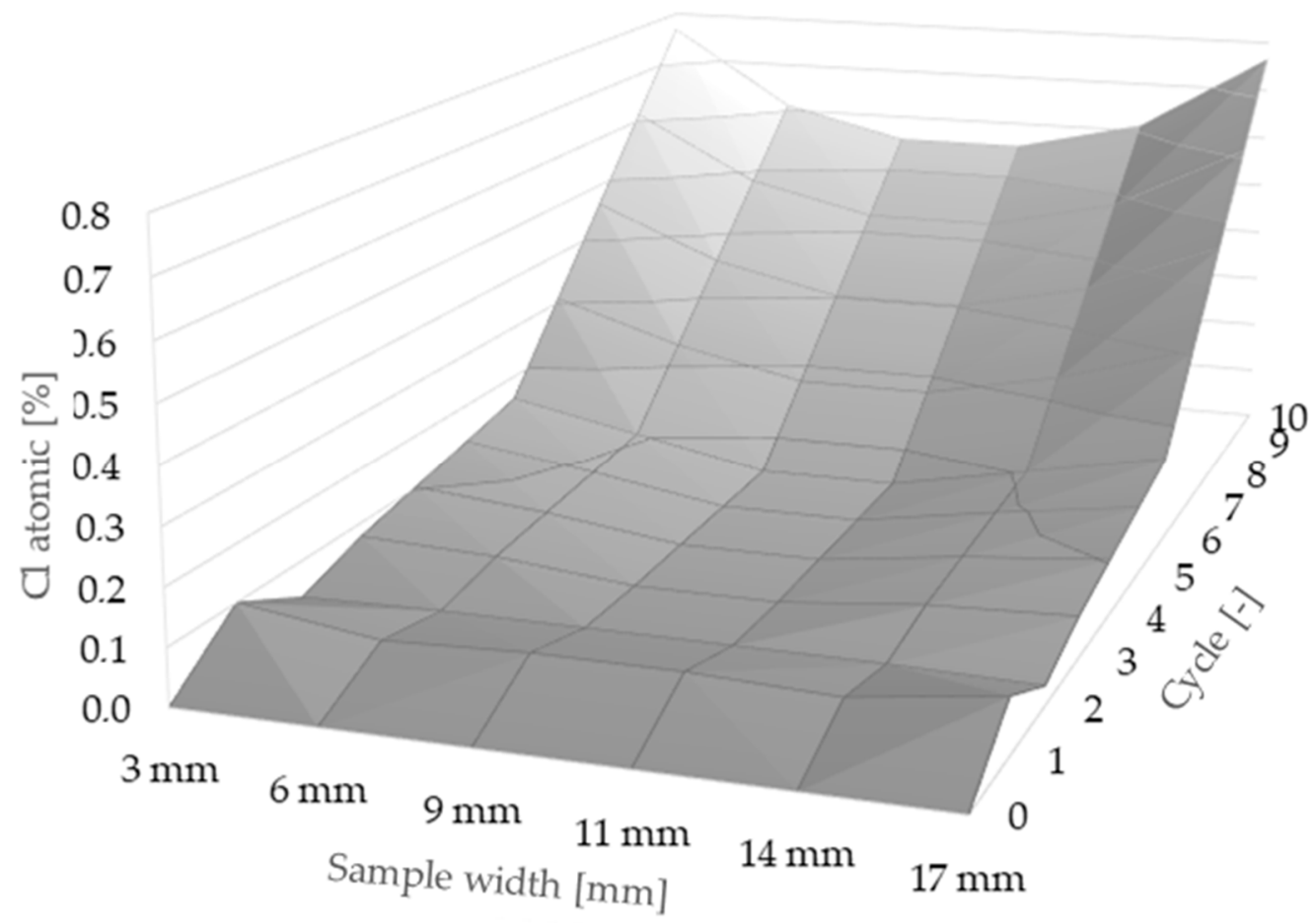

Figure 2. Elementary distribution of chlorine content (atomic\%) within the cross-section of the specimens for cycle 1, 2, 3, 6, and 10 of $n=2$ samples each spot. For cycles 4, 5, 7, 8, and 9 the values were interpolated.

\subsection{Weathering Effects on Oak Wood}

Natural weathering or aging effects on mechanical, physical, and chemical properties of wood (spruce, fir, oak, scots pine, and western red cedar) have been well studied. Kránitz [32] summarized, that the aging effect usually influences the brittleness of wood, which leads to a decrease in bending, tension and impact bending strength caused by means of UV radiation. In different studies, a negligible to slight decrease in EMC was observed with increased aging of wood [33,34]. In contrast, Erhard [35] observed an increased sorption behaviour of scots pine with increasing weathering. In our own experiments, an increase of the EMC was also observed, both for natural and artificial weathering. The results on the changed EMC values are shown in Figure 3. In the case of naturally weathered oak wood, the ageing effects are assumed, as mentioned in the studies above [33,34]. For artificial weathering with salt spray however, the altered EMC is in a minor way related to the increasing salt concentration in the samples.

In the case of natural weathering of oak wood ANOVA shows only a significant difference between the reference samples and samples after weathering for EMC, but there is no significant decrease in MOE, MOR, $\rho$, and $\alpha$. These results, except EMC, agree with data from the literature, where Sonderegger [33] obtained decreasing sorption values for aged oak and fir and similar sorption values for aged spruce wood. In oak wood, Sonderegger [36] observed a decrease in impact bending strength compared to unaffected reference samples. Sonderegger [36] and Lang [37] explained the decreasing strength properties and the increasing brittleness of wood under natural weathering conditions by the development of micro-cracks caused by the constant change of swelling and shrinkage during the weathering period. 


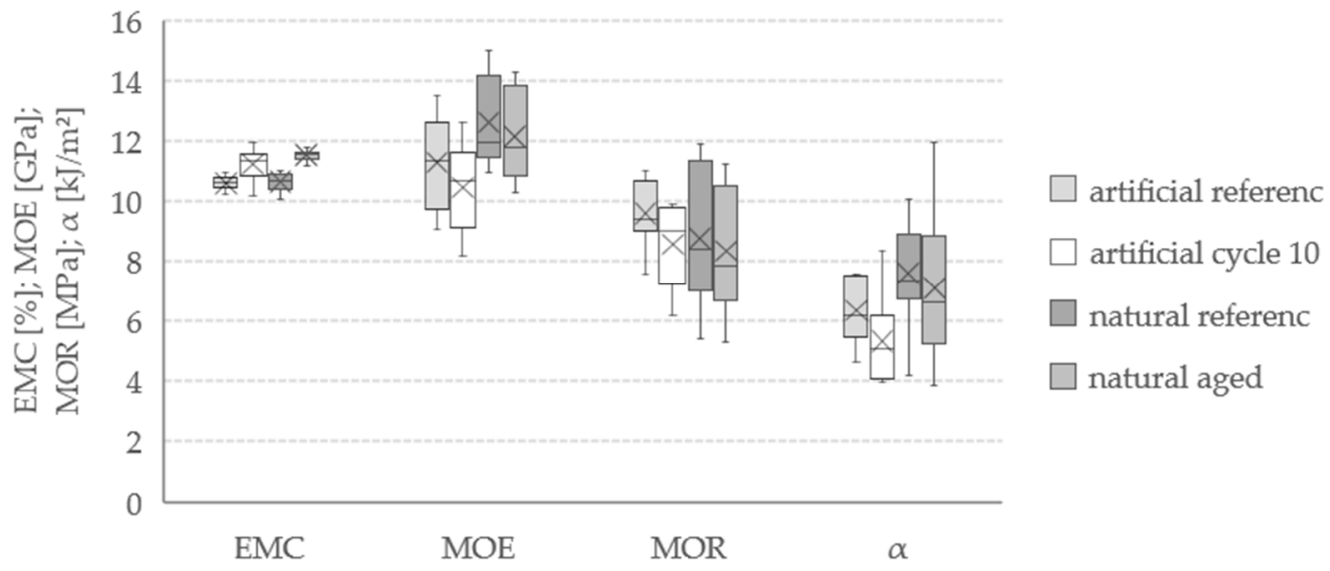

Figure 3. EMC, modulus of elasticity (MOE), bending strength (MOR) and impact bending strength $(\alpha)$ of artificially and naturally weathered oak solid wood ( $n=11$ samples). The whiskers present minimum and maximum values, $\mathrm{x}$ is the mean value and-is the median.

Figure 3 shows the EMC, MOE, MOR, and $\alpha$ of oak wood samples after 10 cycles of artificial weathering and after 14 years of natural weathering as well as for unaffected reference samples. Under artificial and natural weathering, MOR and MOE decreased with increasing exposure time, while EMC increased. The EMC after 10 cycles of artificial weathering was $11.21 \%$. Corresponding reference samples showed an EMC of $10.59 \%$. The EMC of the reference samples for natural weathering showed comparable values with $10.62 \%$. After 10 years of exposure to natural weathering conditions the EMC increases to $11.51 \%$.

With regard to mechanical properties, the average MOE for the reference samples of natural weathering was $12.59 \pm 1.45 \mathrm{GPa}$ (ranging from $10.95 \mathrm{GPa}$ up to $14.95 \mathrm{GPa}$ ) and for artificial weathered samples was $11.26 \pm 1.5 \mathrm{GPa}$ (varying from $9.07 \mathrm{GPa}$ up to $13.74 \mathrm{GPa}$ ). The average MOR of reference samples for natural weathering was $87.46 \pm 23.44 \mathrm{MPa}$ (varying from 53.8 MPa up to $118.9 \mathrm{MPa}$ ) and for artificial weathering $95.86 \pm 11.34 \mathrm{MPa}$ (varying from $75.86 \mathrm{MPa}$ up to $110.04 \mathrm{MPa}$.

Impact bending strength of non-weathered reference samples for the naturally weathered sample set was $75.77 \pm 15.66 \mathrm{~kJ} / \mathrm{m}^{2}$ (varying from $41.73 \mathrm{~kJ} / \mathrm{m}^{2}$ up to $100.36 \mathrm{~kJ} / \mathrm{m}^{2}$ ), whereas lower reference values were observed for the artificially weathered sample set with an average value of $63.43 \pm 9.49 \mathrm{~kJ} / \mathrm{m}^{2}$ (varying from $46.33 \mathrm{~kJ} / \mathrm{m}^{2}$ up to $75.72 \mathrm{~kJ} / \mathrm{m}^{2}$ ). These values are in line with literature values. Sell [38] reported values for impact bending strength for oak solid wood ranging between $50 \mathrm{~kJ} / \mathrm{m}^{2}$ and $74 \mathrm{~kJ} / \mathrm{m}^{2}$ and Wagenführ [39] indicated a very high variation in impact strength from $10 \mathrm{~kJ} / \mathrm{m}^{2}$ up to $160 \mathrm{~kJ} / \mathrm{m}^{2}$. After 14 years natural weathering a decrease of $6.45 \%$ for impact bending strength was observed. For the artificially weathered samples the decrease in impact bending strength was $16.53 \%$.

\subsection{Weathering Effects on Birch Wood}

In Figure $4 \mathrm{a}-\mathrm{d}$ the results of artificial weathering of birch wood for all 10 cycles are shown. The mean value for the reference sample of MOE and MOR were $15.41 \pm 0.76 \mathrm{GPa}$ and $124.46 \pm 7.06 \mathrm{MPa}$, the average value for $\alpha$ was $103.48 \pm 5.86 \mathrm{~kJ} / \mathrm{m}^{2}$, and the mean value for EMC was $9.15 \% \pm 0.36 \%$. 

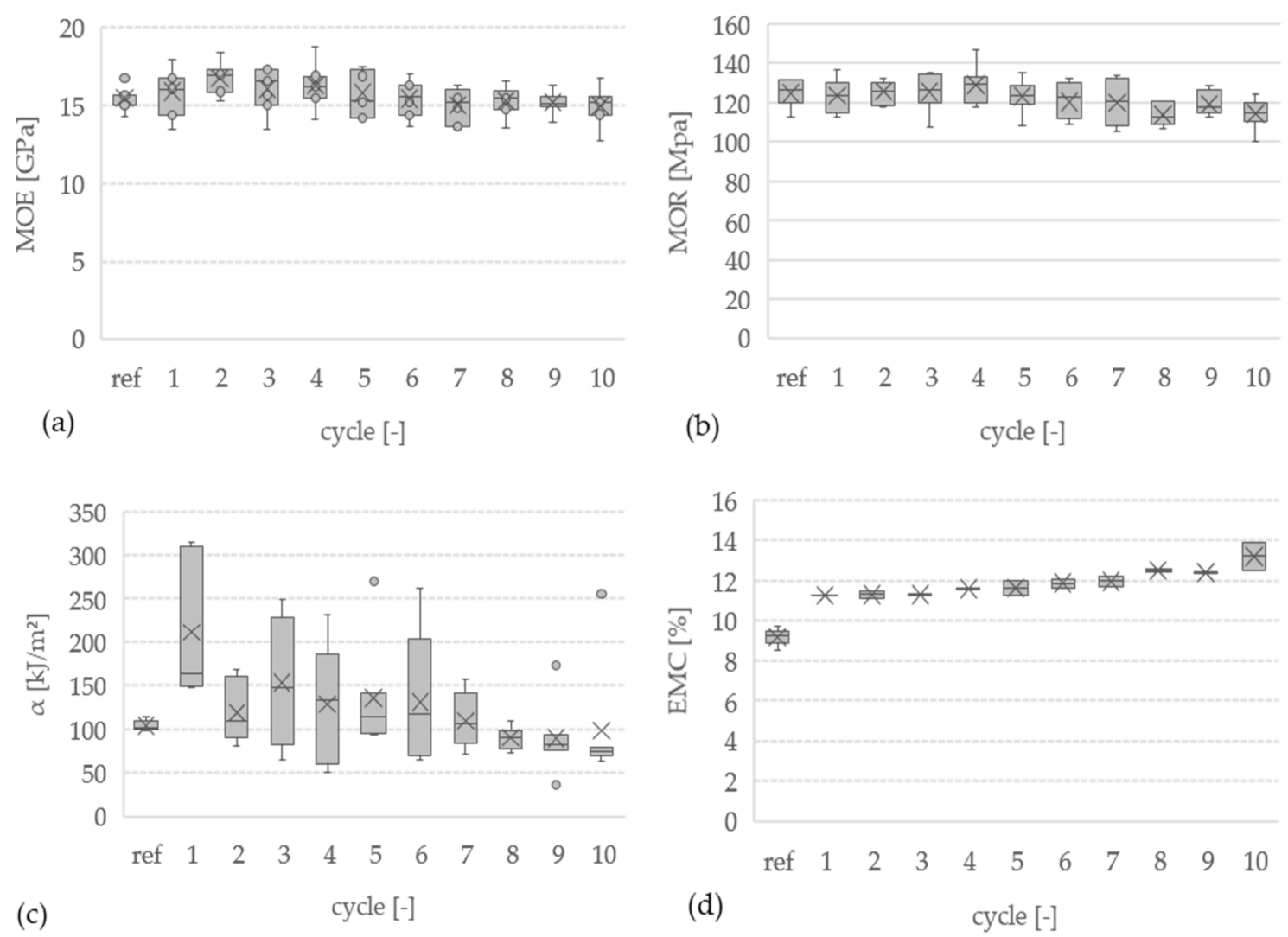

Figure 4. Mechanical and physical properties of artificial weathering for birch solid wood of $n=7$ samples. (a) bending MOE, (b) bending strength, (c) impact bending strength and (d) equilibrium moisture content. The whiskers present minimum and maximum values, $\mathrm{x}$ is the mean value and-is the median.

MOE values of unaffected solid birch wood were reported by Sell [38] (13.3-16.2 GPa) and Wagenführ [39] (14.5 GPa up to $16.5 \mathrm{GPa}$ ) respectively, which is in good agreement with our own values. A sound correlation with the literature values was also observed for the MOR. The values published by Sell [38] range between $120 \mathrm{MPa}$ and $144 \mathrm{MPa}$, whereas Wagenführ [39] again specifies a higher range of $76 \mathrm{MPa}$ up to $155 \mathrm{MPa}$ for MOR. For $\alpha$, Sell [38] gives values between $75 \mathrm{~kJ} / \mathrm{m}^{2}$ and $100 \mathrm{~kJ} / \mathrm{m}^{2}$, which is slightly below the values observed in this study, while Wagenführ [39] gives a broader range from $45 \mathrm{~kJ} / \mathrm{m}^{2}$ to $130 \mathrm{~kJ} / \mathrm{m}^{2}$ for $\alpha$, thus covering the values observed in this study.

Figure $4 \mathrm{a}, \mathrm{b}$ shows the changing values for the MOE and MOR of the individual climate cycles. An increase in MOE from reference to cycle 2 of about $8.41 \%$ was observed, whereas the MOR increases continuously from reference up to cycle 4 of about $3.41 \%$. With regards to MOE, the stiffness shows a slight decrease beginning at cycle 3 till the end of the 10 weathering cycles, whereas for MOR a decrease of the values was only observed starting with cycle 5 . For the full 10 weathering cycles, only a small decrease in the MOE and MOR of about $3.2 \%$ and $8.21 \%$, respectively, was observed compared to the reference samples.

With regard to the impact bending strength, which is shown in Figure $4 \mathrm{c}$, a strong increase of $104.16 \%$ was observed after the first weathering cycle compared to the reference samples. Sample size was seven and the samples were randomly selected and tested and weathered in a standardized test laboratory of the company MAGNA, thus it is assumed, that a systematic error or treatment can be excluded. After cycle 1, a decrease in $\alpha$ was observed, which then increases again to cycle 3 . After cycle 3, a continuous decrease in $\alpha$ was observed until cycle 10. In total a slight decrease in impact bending strength from reference to cycle 10 of about $4.94 \%$ was observed. If one summarizes 
the observed effects on the mechanical properties for 10 weathering cycles, it can be concluded that with regard to MOE, MOR, and $\alpha$, only a slight decrease of the characteristic values is to be expected. The reduction of MOE and MOR can be explained by previous studies [22,31,40]. However, the high scattering as well as the increase in impact strength after cycles 1 and 3 leave a number of questions unanswered, which will be dealt with in more detail below.

Figure $4 \mathrm{~d}$ shows the alternating values for the EMC of the individual climate cycles. An abrupt increase was observed after the first cycle of artificial weathering. Overall, the EMC increases from reference $(9.15 \%)$ to cycle $10(13.18 \%)$ for birch solid wood (increasing EMC of about $4 \%$ ).

According to Wilson [40], the moisture content influences the mechanical properties. Within the hygroscopic range of wood, the MOE decreases by about $2 \%$ per $1 \%$ increase in moisture content. Kollmann [22] presented a decrease in MOR of about $4 \%$ with increasing moisture content of about $1 \%$. Therefore, a certain part of the decrease in MOE and MOR can be explained by the change in EMC, whereby the increase in EMC is certainly intensified by the hygroscopic behaviour of the salt used during the artificial weathering process, which will be discussed in the section of elementary analysis.

With regard to the impact bending strength, Kollmann [22] and Niemz [31] reported, that there is little to no influence on $\alpha$ for air-dried wood with regard to moisture content. This is in line with the results between reference and artificial weathered samples. However, the EMC is additionally influenced by the deposition of salt within the microstructure of wood. With regard to artificial weathering in salt environment there is little literature available $[24,25,41]$.

The chosen alternating cyclic corrosion test is normally used to detect the corrosion of coated or uncoated components. In the automotive industry, structural components consist primarily of steel and aluminium. Unprotected, these materials show comparatively low media resistance in artificial weathering tests with salt solution [42]. Corrosion, mass loss, degradation, and a significant decrease in mechanical properties are consequences of cyclic corrosion tests [42-44]. There is no experience available for wood in the construction of vehicles regarding its resistance to various media. For this reason, experts from the automotive industry have assumed that wood behaves similarly to metal and does not pass this test. Correctly used, wood components in vehicles are protected by their construction, i.e., waterlogging, UV radiation, and wood-destroying organisms can be excluded. If these mechanisms can be excluded, only a minor aging process occurs, which has no significant influence on the stiffness and strength of wood [19]. Therefore, the comparison of natural and artificial weathering was chosen for two reasons. On the one hand, biological degradation and waterlogging can be excluded if the constructive protection is done successfully and on the other hand, the natural weathering period of 14 years is comparable with the defined artificial weathering period. The interaction of wood and salt is scarcely described in the literature and therefore this study was conducted.

\subsection{Elementary Analysis}

As mentioned above, deposition of salt within the wood substrate has a significant effect on EMC. During artificial weathering sodium chloride solution diffused into the wood material. Figure 2 shows the distribution of the chlorine content $(\mathrm{CC})$ within the cross section of the birch solid wood specimens as a mean value for cycle $1,2,3,6$ and 10 of two samples $(n=2)$ for each measuring spot. Comparing cycle 1 and 10 , the amount of chlorine increases from 0.08 at $\%$ up to 0.64 at $\%$. In addition, the ratio of the CC between the edge and the middle of a specimen increases with increasing cycle time. After the first cycle an increase in salt concentration is observed. It is remarkable that the concentration does not increase further in the following cycles 2 and 3, but rather remains at the same level or even decreases. It is assumed that in this phase of artificial weathering further salt transport takes place by diffusion into the centre of the sample. As a result, the concentration in the outer layers even decreases slightly. It is assumed that in these first cycles not only is salt deposited but it is also leached out in the outer layers. In any case, both effects would explain the decrease of the salt concentration in the outer layers of the samples after cycle 2 and 3. Only when the entire sample is completely saturated, with a basic 
concentration of $0.1 \%$, does a further steep increase in the salt concentration occur, as was the case after cycle 6.

Figure $5 \mathrm{a}$, b shows the CC distribution over the cross section of the birch solid wood samples for all weathering cycles. Additionally, the CC concentrations are compared to the EMC and the mechanical properties. In their natural state, birch and oak have a very low concentration of inorganic substances. Fengel and Wegener [45] reported values for ash content for European birch (Betula verrucose Roth) and English oak wood (Quercus robur L.) of about $0.3 \%$. With the 10 main components listed, the conclusion can be drawn that the sodium chloride content is negligibly low for these species. To prove the increase in salt concentration due to artificial weathering, EDX measurements were carried out for cycles 1 , $2,3,6$, and 10. Due to the negligible natural concentration of salt in the reference samples, the EDX measurement for the reference samples was not performed.

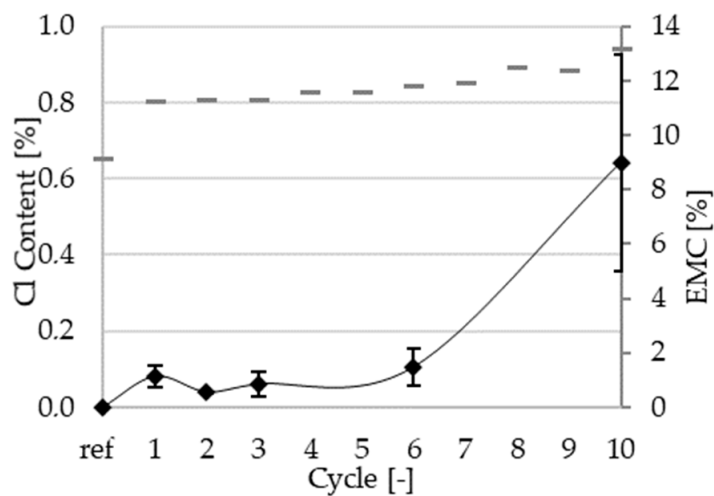

(a)

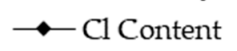

$-\mathrm{EMC}$

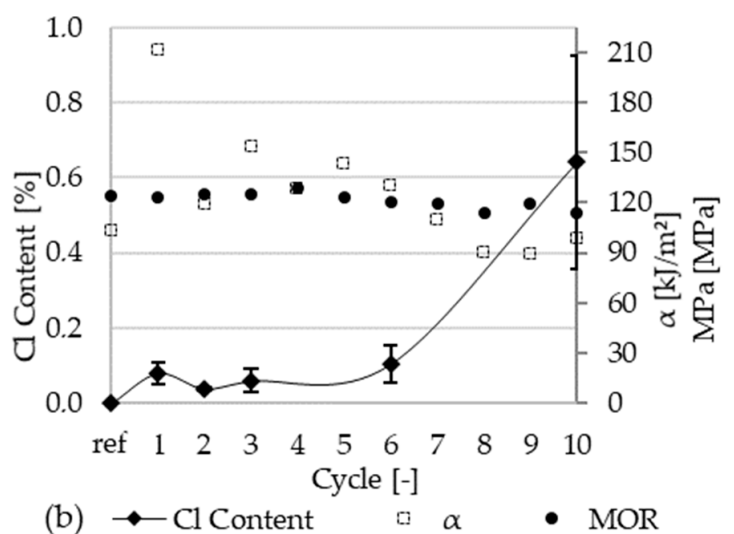

Figure 5. $\mathrm{Cl}$ content (\%) (CC) of $n=6$ samples where the standard deviation is given and the data points are connected by smoothed lines. (a) compares the equilibrium moisture content (\%) with the $\mathrm{CC}$ and (b) shows MOR and $\alpha$ compared to CC of artificial weathering for birch solid wood for each cycle of $n=7$ samples.

Figure 5 clearly shows that the total concentration of sodium chloride increases with the first cycle and decreases about $50 \%$ after cycle 2 and then increases again to about the level of cycle 1 by cycle 6 . The standard deviation of the measured values increases slightly until cycle 6 . After cycle 6 there is a further increase in the sodium chloride concentration and at the same time a significant increase in the scatter of the CC over the cross section of the samples.

In Figure 5a the CC concentration is compared to the EMC. It can be assumed that the increase of the EMC can be at least partly explained by the increase of the CC concentration, since both values correlate, more or less, well for the observed sample. Corresponding to CC, an increase from the reference samples up to cycle 10 can be observed for EMC, with an abrupt rise in EMC from $9.2 \% \pm 0.36 \%$ to about $11.3 \% \pm 0.16 \%$ for cycle 1 . In contrast to the fluctuating salt concentrations for cycle 2 to 6 , the EMC shows an almost constant value up to cycle 5 and then increases continuously up to about $13.2 \% \pm 0.71 \%$ at cycle 10 .

As seen in Figure $4 \mathrm{a}, \mathrm{b}$ and Figure $5 \mathrm{~b}$ the $\mathrm{CC}$ has negligibly low influence on MOE and MOR. In contrast $\alpha$ is already significantly influenced by the increasing salt concentration in the samples during the first cycles, as can be seen in Figure 5b. As mentioned above $\alpha$ increased by $104 \%$ compared to the reference samples after the first cycle. In addition to the change in EMC, it is assumed that the change in CC content also has an influence on $\alpha$. The assumption, that CC has an effect on $\alpha$, is supported by the values gained after cycle 2 , where a significantly lower CC concentration and a lower impact strength were observed. Comparing cycle 1 and cycle 2, the CC content decreases by about $50 \%$ and the impact strength decreases by $43 \%$, which is almost at the level of the reference samples. From cycle 2 to cycle 3, the CC increases again from $0.04 \%$ to $0.06 \%$, which results in a new 
increase of $\alpha$ from $118.94 \mathrm{~kJ} / \mathrm{m}^{2}$ to $153.2 \mathrm{~kJ} / \mathrm{m}^{2}$. This further supports the assumption that the increasing $\mathrm{CC}$ is accompanied by an increasing EMC and thus in combination positively influences the impact bending strength during the first cycles. After cycle $6, \alpha$ decreases rapidly to $98.37 \mathrm{~kJ} / \mathrm{m}^{2}$ by cycle 10 , while the CC further increases significantly. We therefore assume, that with an increasing number of weathering cycles, there are additional mechanisms that have a negative effect on $\alpha$. Perhaps the input of salt in combination with the changing climatic conditions leads to increasing swelling and shrinkage phenomena and thus to macro-mechanical effects.

In this study, artificial weathering tests were used in which one cycle approximately represents a natural weathering of 1.4 years. This factor is an empirical value based on the experience of the company MAGNA. It is a rough estimate in order to transfer the results from accelerated weathering to natural ageing processes of vehicle components (mainly made of plastics and metals). Due to the advancing weathering in the climate chamber, the samples are exposed to strong mechanical stresses. Oltean [46] summarized that strongly changing climate conditions lead to high tensile stresses within the wood structure and cause microcracks. This both influences and reduces the mechanical properties of wood. Furthermore, Sonderegger [36] and Lang [37] observed that microcracks have a particularly strong influence on the impact bending strength of aged wood. On the basis of the elementary analyses it can be assumed, that the CC and EMC have less influence on the mechanical properties, the longer the mechanical stress is caused by the climatic exposure. Therefore, the mechanical properties of solid birch and oak wood are strongly influenced by the $\mathrm{NaCl}$ content in the initial cycles, while emerging mechanical stresses initiated during the weathering process influence the mechanical properties in later cycles. Despite an extensive literature research, no literature was found confirming this statement. EDX analyses should therefore be considered as a qualitative interpretation of the collected results.

Based on the results presented above, the initially proposed hypothesis can be confirmed, where wood has a good resistance to various weather conditions. In addition, bending strength and impact bending strength are only slightly affected by artificial and natural weathering. Changing climatic conditions and spraying with common salt are therefore no limitations for wood as a structural component in vehicle construction.

\section{Conclusions}

The present study investigated accelerated aging processes by means of changing climate conditions and natural weathering effects on solid oak and birch wood. For the purpose of artificial weathering, the medium salt was chosen in order to compare wood with materials currently used in the automotive industry. With regard to natural aging effects, oak and birch wood were exposed to outdoor conditions over 14 years. The aim was to investigate the effects of natural and artificial weathering on the mechanical and physical properties of wood.

Our results confirm that alternating climate conditions in a salty environment increases the EMC due to the higher hygroscopic behaviour of $\mathrm{NaCl}$, while MOE, MOR and $\alpha$ are less effected. In terms of artificial weathering decreasing MOE, MOR, and impact bending strengths of about 7.33, 10.87, and $16.29 \%$ for oak and 3.2, 8.21, and $4.03 \%$ for birch were observed. The EMC for birch wood increases from $10.35 \%$ to $11.81 \%$ and for oak wood from $11.36 \%$ to $11.97 \%$. Comparable results were obtained for the natural weathering process. The EMC of oak after salt spraying during artificial weathering does not exceed the increase of EMC of oak after long-term outside weathering without any salt spraying. The influence of salt can therefore be considered minor.

Based on the reported results it can be concluded that wood has good resistance to various weather conditions, with only minor changes in MOE, MOR, and $\alpha$. In terms of media resistance to salt solutions, wood is a suitable material for structural applications in the automotive industry.

Author Contributions: Conceptualization, A.S. and U.M.; methodology, A.S.; validation, A.S. and M.P.; formal analysis, A.S.; investigation, A.S. and R.S.; resources, A.S., R.S., C.K., and T.J.; data curation, A.S. and R.S.; writing-original draft preparation, A.S.; writing-review and editing, U.M.; visualization, A.S.; supervision, U.M. All authors have read and agreed to the published version of the manuscript. 
Funding: The results presented in this study are part of the research project "WoodC.A.R. (http://www.woodcar. eu/index.html)" (Project No.: 861.421). Financial support by the Austrian Research Promotion Agency (FFG), Styrian Business Promotion Agency (SFG), Standortagentur Tirol, and the companies Collano AG, DOKA $\mathrm{GmbH}$, DYNAmore $\mathrm{GmbH}$, EJOT Austria GmbH, Forst-Holz-Papier, Holzcluster Steiermark GmbH, IB STEINER, Lean Management Consulting GmbH, Magna Steyr Engineering GmbH \& Co KG, MAN Truck \& Bus AG, Mattro Mobility Revolutions GmbH, Volkswagen AG, and Weitzer Parkett GmbH \& Co KG.

Acknowledgments: The performance of the alternating climate tests by Christian Schalcher (Process \& Material Engineering, MAGNA STEYR FAHRZEUGTECHNIK AG \& CO KG) is gratefully acknowledged.

Conflicts of Interest: The authors declare no conflict of interest.

\section{References}

1. Friedrich, H.E. Leichtbau in Der Fahrzeugtechnik; Springer: Stuttgart, Germany, 2017; ISBN 3658122951.

2. Baumann, G.; Stadlmann, A.; Kurzböck, C.; Feist, F. Crashsichere Holzverbundwerkstoffe in Leichtbaukarosserien der Zukunft. ATZ-Automob. Zeitschrift 2019, 121, 54-59. [CrossRef]

3. Mair, C.; Zimek, M.; Stern, T.; Baumgartner, R.J. Sustainability performance of wood based materials: A systemic assessment of lightweight materials for the mobility sector. In Proceedings of the 24th Annual ISDRS Conference, Messina, Italy, 13-15 June 2018.

4. Kohl, D.; Link, P.; Böhm, S. Wood as a Technical Material for Structural Vehicle Components. Procedia CIRP 2016, 40, 557-561. [CrossRef]

5. Leitgeb, W.; Kerschbichler, S.; Jost, T.; Mayrhofer, P.; Wagner, W.; Müller, U. Holz im strukturellen Fahrzeugbau. In Proceedings of the IHD, Konferenzproceedings-2. Interdisziplinäres Fahrzeugkolloquium, Dresden, Germany, 15-16 January 2016; pp. 1-118.

6. Müller, U.; Jost, T.; Kurzböck, C.; Stadlmann, A.; Wagner, W.; Kirschbichler, S.; Baumann, G.; Feist, F. Crash simulation of wood and composite wood for future automotive engineering. Wood Mater. Sci. Eng. 2019. [CrossRef]

7. Jost, T.; Müller, U.; Feist, F. Wood Composites for Future Automotive Engineering?-Basic Requirement: Crash Simulation of Wood-Based Components Holzverbundwerkstoffe im Automobilbau der Zukunft?-Grundvoraussetzung: Crashsimulation von Holzkomponenten. Konstruktion 2018, 10, 74-82.

8. EC European Commission. A Sustainable Bioeconomy for Europe: Strengthening the Connection between Economy, Society; COM(2018) 673 final; EC European Commission: Brussel, Belgium, 2018.

9. Asada, R.; Cardellini, G.; Mair-Bauernfeind, C.; Wenger, J.; Haas, V.; Holzer, D.; Stern, T. Effective bioeconomy? A MRIO-based socioeconomic and environmental impact assessment of generic sectoral innovations. Technol. Forecast. Soc. Change 2020, 153, 119946. [CrossRef]

10. Feist, F.; Baumann, G.; Müller, U.; Stadlmann, A.; Kumpenza, C. Aufprallschutz, insbesondere Seitenaufprallschutz für eine Fahrzeugtür 2020. Available online: http://see-ip.patentamt.at/NPatentSuche/ SearchResult (accessed on 22 July 2020).

11. Müller, U.; Kirschbichler, S.; Leitgeb, W.; Jost, T. The Road from Creating a Material Model to a Structural Component of Wood for Automotive Applications. In Proceedings of the TU Verlag; Füssl, J., Bader, T.K., Eberhardsteiner, J., Eds.; The CompWood 2017 Programme \& Book of Abstracts. TU Verlag: Vienna, Italy, 2017.

12. Li, Z; He, M. Finite Element Modeling and Parametric Analysis of Timber-Steel Hybrid Structures. Struct. Des. Tall Spec. Build. 2014, 23, 1045-1063. [CrossRef]

13. Erler, K. Holz im Außenbereich: Anwendungen, Holzschutz, Schadensvermeidung; Springer: Berlin/Heidelberg, Germany, 2013; ISBN 3034881118.

14. Flanagan, J.; Schütze, P.; Dunne, C.; Twomey, B.; Stanton, K.T. Use of a blast coating process to promote adhesion between aluminium surfaces for the automotive industry. J. Adhes. 2020, 96, 580-601. [CrossRef]

15. Luckeneder, G.; Autengruber, R.; Stellnberger, K.-H.; Kurz, J.F.T. Corrosion Protection of Galvanized Press-Hardening Steel: Main Influencing Factors and Mechanisms. In Proceedings of the Galvatech 2015 Conference Proceedings, Toronto, ON, Canada, 31 May-4 June 2015; pp. 868-875.

16. Vargel, C. Corrosion of Aluminium; Elsevier: Amsterdam, The Netherlands, 2004; ISBN 0080444954.

17. Makar, G.L.; Kruger, J. Corrosion of magnesium. Int. Mater. Rev. 1993, 38, 138-153. [CrossRef] 
18. Scheiding, W.; Grabes, P.; Haustein, T.; Haustein, V.; Nieke, N.; Urban, H.; Weiß, B. Holzschutz: Holzkunde-Pilze und Insekten-Konstruktive und chemische Maßnahmen-Technische Regeln-Praxiswissen; Carl Hanser Verlag GmbH Co KG: Leipzig, Germany, 2016; ISBN 978-3-446-44777-6.

19. Müller, U.; Müller, H.; Teischinger, A. Durability of wood adhesives in 50 year old aircraft and glider constructions. Wood Res. 2004, 49, 25-34.

20. ÖNORM EN 350 Dauerhaftigkeit von Holz und Holzprodukten-Prüfung und Klassifikation der Dauerhaftigkeit von Holz und Holzprodukten Gegen Biologischen Angriff; Austrian Standards: Vienna, Austria, 2017.

21. Müller, U.; Feist, F.; Jost, T. Wood composites in the automotive industry of the future? Assumed crash tests and simulation of wood materials. Holztechnologie 2019, 5-15. [CrossRef]

22. Kollmann, F. Technologie des Holzes und der Holzwerkstoffe, 2nd ed.; Springer: Berlin/Heidelberg, Germany, 1951.

23. Phleger, C.F. Effect of salinity on growth of a salt marsh grass. Ecology 1971, 52, 908-911. [CrossRef]

24. Parida, A.K.; Jha, B. Salt tolerance mechanisms in mangroves: A review. Trees Struct. Funct. 2010, 24, $199-217$. [CrossRef]

25. Tintner, J.; Smidt, E.; Tieben, J.; Reschreiter, H.; Kowarik, K.; Grabner, M. Aging of wood under long-term storage in a salt environment. Wood Sci. Technol. 2016, 50, 953-961. [CrossRef]

26. 11997-1, D.E.I. Paints and Varnishes_Determination of Resistance to Cyclic Corrosion Conditions_Part 1: Wet (Salt Fog)/Dry/Humid (ISO 11997-1:2017); EN ISO 11997-1:2017; ISO: Berlin, Germany, 2017. (In German)

27. DIN 52186 Prüfung von Holz-Biegeversuch; Wien, Austria. Available online: https://literatur.thuenen.de/ digbib_extern/dk040246.pdf (accessed on 30 August 2020).

28. DIN 52189 Prüfung von Holz-Schlagbiegeversuch; Bestimmung der Bruchschlagarbeit; Wien, Austria. Available online: http://www.woodcar.eu/wa_files/muller\%20feist\%20jost_dresden.pdf (accessed on 30 August 2020).

29. ISO 554 Normalklimate für die Konditionierung und/oder Prüfung: Anforderungen; ISO: Geneva, Switzerland, 1976.

30. DIN 52182 Prüfung von Holz-Bestimmung der Rohdichte; 1976. Available online: https://iteratur.thuenen. de/digbib_extern/dk040246.pdf (accessed on 30 August 2020).

31. Niemz, P.; Sonderegger, W. Holzphysik: Physik des Holzes und der Holzwerkstoffe; Carl Hanser Verlag GmbH Co KG: Zürich, France, 2017; ISBN 3446445463.

32. Kránitz, K.; Sonderegger, W.; Bues, C.T.; Niemz, P. Effects of aging on wood: A literature review. Wood Sci. Technol. 2016, 50, 7-22. [CrossRef]

33. Sonderegger, W.; Kránitz, K.; Bues, C.T.; Niemz, P. Aging effects on physical and mechanical properties of spruce, fir and oak wood. J. Cult. Herit. 2015, 16, 883-889. [CrossRef]

34. Obataya, E. Effects of natural and artificial ageing on the physical and acoustic properties of wood in musical instruments. J. Cult. Herit. 2017, 27, S63-S69. [CrossRef]

35. Erhardt, D.; Mecklenburg, M.F.; Tumosa, C.S.; Olstad, T.M. New vs old wood: Differences and similarities in physical, mechanical, and chemical properties. ICOM Comm. Conserv. Prepr. 1996, 2, 903-910.

36. Sonderegger, W.; Niemz, P. The influence of compression failure on the bending, impact bending and tensile strength of spruce wood and the evaluation of non-destructive methods for early detection. Holz als Rohund Werkst. 2004, 62, 335-342. [CrossRef]

37. Lang, A. Charakterisierung des Altholzaufkommens in Deutschland: Rechtliche Rahmenbedingungen, Mengenpotenzial, Materialkennwerte; Wiedebusch: Hamburg, Germany, 2004.

38. Sell, J. Eigenschaften und Kenngrößen von Holzarten; Baufachverlag AG: Zürich, Framce, 1989.

39. Wagenführ, R. Holzatlas 6; VEB Fachbuchverlag: Leipzig, Germany, 2006; ISBN 978-3-446-40649-0.

40. Wilson, T.R.C. Strength-Moisture Relations for Wood; US Dept. of Agriculture: Washington, DC, USA, 1932.

41. Willianzs, R.S.; Feist, W.C. Wood Modified By Inorganic Salts: Mechanism Repellency and Iiimensional Stability of Wood Modifieid with Chromium (111) Nitrate Versus Chromic Acid. Wood Fiber Sci. 1985, 17, 184-198.

42. Rodriguez, J.J.S.; Hernandez, F.J.S.; Gonzalez, J.E.G. The effect of environmental and meteorological variables on atmospheric corrosion of carbon steel, copper, zinc and aluminium in a limited geographic zone with different types of environment. Corros. Sci. 2003, 45, 799-815. [CrossRef]

43. Song, G.; Johannesson, B.; Hapugoda, S.; StJohn, D. Galvanic corrosion of magnesium alloy AZ91D in contact with an aluminium alloy, steel and zinc. Corros. Sci. 2004, 46, 955-977. [CrossRef]

44. Apostolopoulos, C.A. The influence of corrosion and cross-section diameter on the mechanical properties of b500 c steel. J. Mater. Eng. Perform. 2009, 18, 190-195. [CrossRef] 
45. Fengel, D.; Wegener, G. Wood: Chemistry, Ultrastructure, Reactions; Walter de Gruyter: Berlin, Germany; New York, NY, USA, 1989; ISBN 3-11-012059-3.

46. Oltean, L.; Teischinger, A.; Hansmann, C. Influence of temperature on cracking and mechanical properties of wood during wood drying-A review. BioResources 2007, 2, 789-811. [CrossRef]

(C) 2020 by the authors. Licensee MDPI, Basel, Switzerland. This article is an open access article distributed under the terms and conditions of the Creative Commons Attribution (CC BY) license (http://creativecommons.org/licenses/by/4.0/). 